\title{
GESTÃO DOCUMENTAL COMO APORTE PARA A PRESERVAÇÃO DA HISTÓRIA E DA MEMÓRIA NA ERA DIGITAL: ESTUDO DE CASO DESENVOLVIDO NO INSTITUTO FEDERAL BAIANO
}

\author{
Anderson Santana de Souza \\ Mestre em Gestão e Tecnologias Aplicadas a Educação. Universidade do Estado da Bahia - \\ UNEB. Instituto Federal Baiano - IF Baiano \\ E-mail: anderson.santana@ifbaiano.edu.br
}

\begin{abstract}
RESUMO
Este artigo tem como objeto a análise da Preservação da História e Memória contida nos Documentos no Instituto Federal Baiano (IF Baiano). Tem como problema de pesquisa a criação indiscriminada dos documentos e falta de padronização e normatização dos procedimentos para preservação dos documentos. O objetivo do trabalho consiste em propor a criação de uma estrutura capaz de gerenciar, integralizar e definir Políticas Arquivísticas, considerando os ditames da Era Digital, para a preservação da Informação a longo prazo. O percurso metodológico se iniciou por um Estudo Exploratório, contemplando análise bibliográfica e documental, que possibilitou a construção do arcabouço teórico para a pesquisa. Foi empregada abordagem quantitativa e qualitativa para a realização da análise dos dados. O universo da pesquisa foi constituído por 32 servidores do Instituto, divididos em três grupos: servidores que realizam atividades em setores de Protocolo, Arquivo Administrativo e Arquivo Acadêmico, e, para cada um desses grupos foi elaborado um questionário diferenciado e aplicado via e-mail. Os resultados da pesquisa indicam que a maioria dos servidores que realizam as atividades relacionadas a Arquivo e Protocolo não são profissionais especializados na área, nem possuem formação básica em Gestão de Documentos. Além disso, o Instituto não possui setores com estrutura física e equipamentos que possibilitem a realização correta dessas atividades. Com a realização da pesquisa, foi possível a análise da realidade da Instituição e a elaboração do Projeto de implantação de Softwares Livres, para a Gestão e Preservação dos Documentos Digitais.
\end{abstract}

Palavras-chave: Documentos arquivísticos digitais. Gestão Documental. Preservação da História e Memória.

\section{DOCUMENTARY MANAGEMENT AS A CONTRIBUTION TO THE PRESERVATION OF HISTORY AND MEMORY IN THE DIGITAL ERA: CASE STUDY DEVELOPED AT THE FEDERAL INSTITUTE BAIANO}

\begin{abstract}
This article aims to analyze the Preservation of History and Memory contained in the Documents at the Federal Institute of Bahia (IF Baiano). Its research problem is the indiscriminate creation of documents and the lack of standardization and standardization of procedures for preservation of documents. The objective of this work is to propose the creation of a structure capable of managing, integrating and defining Archival Policies, taking into account the dictates of the Digital Era, for the preservation of Information in the long term. The methodological course was initiated by an Exploratory Study, contemplating bibliographical and documentary analysis, that made possible the construction of the theoretical framework for the research. Quantitative and qualitative approach was used to perform the data analysis. The research universe consisted of 32 public servant of the Institute, divided into three groups: public servant that carry out activities in the Protocol, Administrative File and Academic Archives sectors, and for each of these groups a differentiated questionnaire was elaborated and applied via e-mail. The results of the research indicate that most of the public servant that perform the activities related to Archive and Protocol are not professionals specialized in the area, nor do they have basic training in Document Management. In addition, the Institute does not have sectors with physical structure and equipment that allow the correct accomplishment of these activities. With the accomplishment of the research,
\end{abstract}


it was possible to analyze the reality of the Institution and the elaboration of the Project of implantation of Free Software, for the Management and Preservation of Digital Documents.

Keywords: Digital archival documents. Document management. Preservation of History and Memory.

\title{
GESTIÓN DOCUMENTAL COMO APORTE PARA LA PRESERVACIÓN DE LA HISTORIA Y LA MEMORIA EN LA ERA DIGITAL: ESTUDIO DE CASO DESARROLLADO EN EL INSTITUTO FEDERAL BAIANO
}

\begin{abstract}
RESUMEN
Este artículo tiene como objeto el análisis de la Preservación de la Historia y Memoria contenida en los Documentos en el Instituto Federal Baiano (IF Baiano). Tiene como problema de investigación la creación indiscriminada de los documentos y falta de estandarización y normalización de los procedimientos para preservación de los documentos. El objetivo del trabajo consiste en proponer la creación de una estructura capaz de administrar, integralizar y definir políticas archivísticas, considerando los dictámenes de la era digital, para la preservación de la información a largo plazo. El recorrido metodológico se inició por un Estudio Exploratorio, contemplando análisis bibliográfico y documental, que posibilitó la construcción del armazón teórico para la investigación. Se empleó un enfoque cuantitativo y cualitativo para la realización del análisis de los datos. El universo de la investigación fue constituido por 32 servidores del Instituto, divididos en tres grupos: servidores que realizan actividades en sectores de Protocolo, Archivo Administrativo y Archivo Académico, y para cada uno de esos grupos se elaboró un cuestionario diferenciado y aplicado vía e-mail. Los resultados de la investigación indican que la mayoría de los servidores que realizan las actividades relacionadas con Archivo y Protocolo no son profesionales especializados en el área, ni poseen formación básica en Gestión de Documentos. Además, el Instituto no posee sectores con estructura física y equipamientos que posibiliten la realización correcta de esas actividades. Con la realización de la investigación, fue posible el análisis de la realidad de la Institución y la elaboración del Proyecto de implantación de Softwares Libres, para la Gestión y Preservación de los Documentos Digitales.
\end{abstract}

Palabras clave: Documentos Archivísticos Digitales. Gestión Documental. Preservación de la Historia y la Memoria.

\section{Introdução}

A sociedade contemporânea está vivendo uma transformação na forma como as pessoas se relacionam, consomem e vivem, em virtude da evolução tecnológica. Neste cenário, surge a necessidade de adequação da administração pública, mais precisamente no que se refere a este estudo, das Instituições de Ensino, para atender de forma mais eficiente as demandas cada vez mais crescentes desta sociedade digital.

O processo educativo dessas instituições é constituído pelos aspectos organizacionais, pelas condições em que se efetiva o ensino-aprendizagem, pelo contexto sociocultural, e pelos processos de organização e gestão da educação.

Os gestores da educação empregam conhecimentos ou estratégias administrativas, e as raízes da gestão educacional fincam-se na teoria geral da administração. Todas as 
decisões principais (planejar, organizar, dirigir e controlar) e de recursos (instalações, espaço, tempo, dinheiro, informações e pessoas) estão presentes na gestão da educação.

Essa gestão trabalha com atores sociais e suas relações com o ambiente, enquanto sujeitos da construção da história humana, gerando participação, corresponsabilidade e compromisso. No intuito de analisar e propor um modelo de gestão da educação, que contemple em sua estrutura uma proposta inovadora para um dos seus aspectos: a Preservação da História e Memória contida nos Documentos, apresenta-se como loco dessa pesquisa o Instituto Federal de Ciência e Tecnologia Baiano - IF Baiano, que foi criado em 29 de dezembro de 2008, a partir da união das antigas Escolas Médias de Agropecuária EMARCs, com as Escolas Agrotécnicas Federais - EAFs, Instituições essas com caminhos já consolidados.

O IF Baiano traçou uma trajetória de crescimento institucional na Bahia, foi estruturado na forma multicampi, e atualmente compreende, além da Reitoria com sede em Salvador, mais catorze Campus, nas cidades de Alagoinhas, Bom Jesus da Lapa, Catu, Guanambi, Governador Mangabeira, Itaberaba, Itapetinga, Santa Inês, Senhor do Bonfim, Serrinha, Teixeira de Freitas, Uruçuca, Valença e Xique-Xique.

Tendo em vista que o IF Baiano é uma instituição em crescimento/expansão, que prioriza a qualidade no ensino e a modernização em suas atividades administrativas, apresenta-se como tema dessa artigo "Gestão documental como aporte para a preservação da História e da Memória na Era Digital", fruto do Trabalho de Mestrado intitulado "Gestão de Documentos na Era Digital”, do Programa de Pós-Graduação Gestão e Tecnologias Aplicadas à Educação (Gestec), da Universidade do Estado da Bahia - UNEB, na perspectiva de analisar a estrutura de gestão atual dos documentos do Instituto, o volume produzido e como são preservados, para que seja possível propor um modelo de gestão capaz de produzir os documentos em formato digital e zelar pela sua autenticidade e manutenção a longo prazo, bem como, inserir a Instituição em um contexto mundial em que, cada vez mais, os documentos estão nascendo digitais.

Os arquivos do IF Baiano, têm sob sua guarda documentos essenciais para a administração do Instituto, no decorrer das atividades de ensino, pesquisa e extensão. Além disso, esses documentos são testemunho da memória da instituição, podendo ser fonte de pesquisa para alunos, professores, historiadores, pesquisadores, entre outros.

$\mathrm{O}$ gerenciamento desses arquivos visa o atendimento eficiente e eficaz das demandas dos órgãos governamentais, assim como das necessidades internas da 
instituição. Através do gerenciamento dos arquivos poderá ser possível aproveitar ao máximo as informações disponíveis, além de facilitar a consulta aos documentos e, consequentemente, otimizar as atividades pedagógicas e administrativas.

A iniciativa em realizar esta pesquisa iniciou-se em função da experiência adquirida como arquivista em três Instituições Federais de Ensino, na Universidade Federal de Minas Gerais (UFMG), na Universidade Federal de Alagoas (UFAL), e atualmente no Instituto Federal Baiano (IF Baiano). Outro fator motivador foi apontar a necessidade de desenvolver na Instituição uma política arquivística para contemplar os documentos digitais, e identificar a forma mais adequada de informatizar os procedimentos de gestão, sem comprometer a preservação dos documentos para o futuro.

Foi apresentado a possibilidade de analisar a estrutura organizacional no que tange à criação, tramitação, uso e preservação dos seus documentos, como mais um fator motivacional importante para o desenvolvimento da pesquisa.

Entre essa análise da estrutura organizacional, estão inseridos alguns aspectos como: o aumento do volume de documentos produzidos e recebidos pela Instituição, as dificuldades de recuperação da informação, a ocupação indevida e desnecessária de espaços para a guarda do acervo, a dificuldade em atender, com maior facilidade e agilidade, às recomendações do Governo Federal em relação à modernização e otimização dos arquivos da Administração Pública, e a ausência de aplicação das normativas arquivísticas.

O motivo principal para a realização da pesquisa foi a realidade encontrada no Instituto no que se refere ao cuidado com seus documentos; serviu como ponto de partida para a problemática da pesquisa: atualmente, no IF Baiano, os documentos produzidos são armazenados indiscriminadamente, expressando falta de padronização e normatização dos procedimentos para todos os Campi, dificultando a recuperação da informação e expondo ao risco de perda de registros que contenham informações de relevância para a administração, para a pesquisa e para a preservação de fatos históricos.

Como resolver essa problemática? Para responder à questão proposta, foi traçado como objetivo geral da pesquisa: Propor a criação de uma estrutura capaz de gerenciar, integralizar e definir Políticas Arquivísticas, considerando os ditames da Era Digital, para a preservação da Informação a longo prazo.

E, a partir do objetivo geral da pesquisa, foi definido como objetivos específicos: 
a) Analisar o quantitativo de produção de documentos no IF Baiano, para que fosse possível mensurar o quantitativo de pessoal e estrutura necessária para o novo modelo proposto de gestão;

b) Avaliar qual a estrutura Sistêmica atenderá melhor as necessidades do Instituto no que tange a gestão, preservação;

c) Identificar qual o nível de conhecimento, em Gestão de Documentos, dos servidores que atuam diretamente com essa atribuição, no intuito de elaborar cursos de capacitação para os mesmos.

Traçados os objetivos, o desenvolvimento da pesquisa exigiu abordar o tema seguindo as referências teóricas de autores como Silva (1984), Thomaz (2004), Castro (1988), Di Mambro (2014), Innarelli (2015), Rondineili (2002), Sayão (2010), Ferreira (2006), Fontana (2014), Smith (1990), Flores (2015/2016), Hildenise Novo (2014), e, a partir daí, foi possível consolidar a fundamentação teórica da pesquisa.

Outras fontes pesquisadas para dar subsídio à realização do trabalho foram as normativas definidas pelo Conselho Nacional de Arquivos (CONARQ), o Modelo de Requisitos para Sistemas Informatizados de Gestão Arquivística de Documentos e as Leis, Decretos e Portarias Arquivísticas.

O Desenvolvimento a seguir, contém o marco teórico do trabalho; contextualiza a Gestão Arquivística na Era Digital, aponta as mudanças que estão ocorrendo no mundo com a substituição do uso do suporte em papel para o suporte digital, identifica modelos de sistemas capazes de gerir, preservar os documentos digitais de forma segura.

\section{A preservação digital}

Durante muitos séculos, o papel foi o principal suporte para registro e armazenamento da informação e do conhecimento. A preservação documental passou por uma grande modificação nos últimos anos, pois historicamente ela era focada nas massas documentais acumuladas, para só depois aplicar métodos de preservação, mas com a criação dos documentos em formato digital, surgiu a dificuldade de checar a autenticidade do mesmo, pois ele é uma cadeia de bits.

O foco da arquivística se transferiu do documento em si para o objetivo de sua criação, e o documento se transformou, de objeto físico em objeto conceitual, controlado por metadados que combinam virtualmente conteúdo, contexto e estrutura. 
A função do metadado é de garantir que o documento eletrônico não se transforme apenas em informação eletrônica e mantenha sua fidedignidade, assegurando seu valor probatório legal. Rondineili relata a função do metadado:

O metadado mapeia as relações administrativa e documentária de um documento eletrônico dentro do sistema de gerenciamento, durante o seu ciclo vital, fornecendo parte do contexto e da estrutura desse documento e, portanto, deve ser preservado (RONDINEILI, 2002, p. 476).

Baseado nessa citação, percebe-se que a fragilidade estrutural da informação digital configura um dos maiores desafios a ser enfrentado pelos pesquisadores e profissionais das áreas de informação e de tantas outras áreas.

Para tanto, foram criados os metadados de preservação que podem ser definidos, de uma forma simples e direta, por Sayão (2010), como a informação que apoia e documenta a preservação de longo prazo de materiais digitais.

Com o intuito de definir o conceito de preservação digital, será apresentada a seguir a citação de Ferreira:

[...] preservação digital consiste na capacidade de garantir que a informação digital permaneça acessível e com qualidades de autenticidade suficientes para que possa ser interpretada no futuro recorrendo a uma plataforma tecnológica diferente da utilizada no momento da sua criação (FERREIRA, 2006, p.20).

A partir do entendimento do conceito acima, procurar-se-á utilizar os estudos em preservação digital de Fontana et al, (2014, p. 12) sobre o MoReq, InterPARES, CTDE, e OAIS, para fundamentar esta pesquisa:

MoReq (Modelo de Requisitos para a Gestão de Registros Eletrônicos) é o padrão utilizado em toda a Europa atualmente. Ele foi a base para a criação do eArq Brasil - Modelo de requisitos para sistemas informatizados de gestão arquivística de documentos, segundo o e-Arq Brasil (2011, p. 15), e do MoReqJus - Modelo de Requisitos para Sistemas Informatizados de Gestão de Processos e Documentos do Poder Judiciário, adotado pelo CNJ (Conselho Nacional de Justiça), segundo informações do sítio do CNJ (2016) (FONTANA et al, 2014, p. 69).

InterPARES (International Research on Permanent Authentic Records in Electronic Systems) - é um projeto composto por pesquisadores de diversos países, com direção da pesquisadora Luciana Duranti, esse grupo realiza Pesquisa Internacional sobre Documentos Arquivísticos Autênticos Permanentes em Sistemas Eletrônicos. Coordenado pela Universidade de British Columbia no Canadá (FONTANA et al, 2014, p. 68).

CTDE (Câmara Técnica de Documentos Eletrônicos) conforme a definição disponível em seu próprio sítio, a CTDE é um grupo de trabalho que tem por objetivo definir e apresentar ao CONARQ normas, diretrizes, procedimentos técnicos e instrumentos legais sobre gestão arquivística e preservação dos documentos digitais, em conformidade com os padrões nacionais e internacionais. Ela foi criada em 1995 pelo Conselho Nacional de Arquivos CONARQ e reestruturada em 2002 (FONTANA et al, 2014, p. 70).

OAIS (Open Archival Information System) esse modelo visa orientar um sistema de arquivo dedicado à preservação e manutenção do acesso a informações digitais em longo prazo e pode ser adotado em instituições que pretendam 
padronizar os formatos de arquivo. É um modelo de referência estandardizado pela ISO 14721 de 2003 e revisada em 2012, traduzida e adaptada no Brasil como SAAI - Sistema Aberto de Arquivamento de informação estandardizado pela NBR 15472 de 2007 (FONTANA et al, 2014, p. 71).

A Consultative Committee for Space Data Systems (CCSDS, 2012) criou um modelo de referência no intuito de padronizar atividades de preservação digital. Esse modelo, OAIS, especifica os principais critérios nos quais iniciativas em preservação digital devem se amparar. Em pouco tempo, o modelo de referência passou a ser uma norma internacional, regulada na International Organization for Standardization - ISO 14721:2003.

Em seguida apresenta-se a figura do modelo OAIS:

Figura 1 - Modelo OAIS

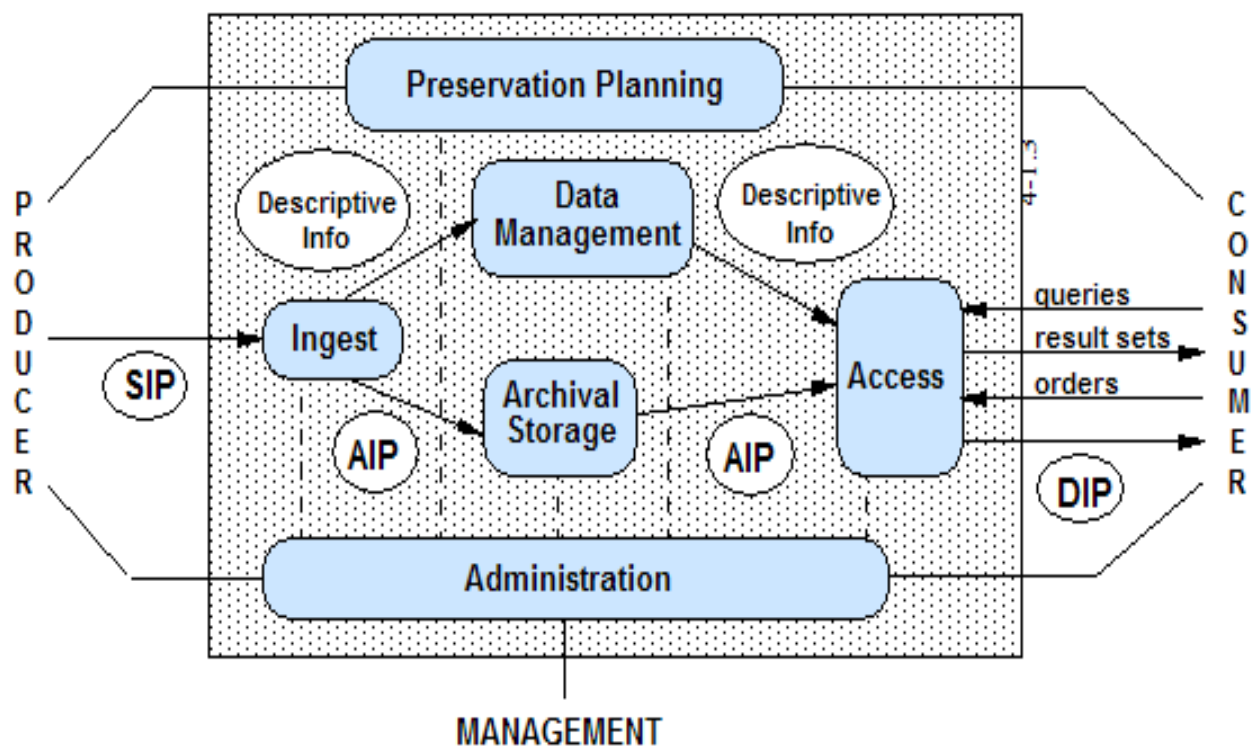

Fonte: Extraído do OAIS (Open Archival Information System).

Analisando a figura anterior, do modelo OAIS, pode-se identificar três partes distintas:

a) Produtor: pessoas ou sistemas que fornecem a informação a ser submetida e preservada via pacotes de informação;

b) Administrador: entidade responsável pelo estabelecimento de políticas e regras gerais do arquivo, como a escolha do formato a ser adotado como padrão para acesso e preservação de longo prazo; 
c) Consumidor: pessoas ou sistemas que irão interagir com os serviços OAIS, sejam através de um repositório ou sistema de gerenciamento arquivístico, são aqueles que acessam as informações e que são capazes de compreender a informação preservada.

Para fundamentar a pesquisa, foi realizada uma revisão documental também na área jurídica, para compreender a preservação de documentos digitais a partir do entendimento da cadeia de custódia por Nóbrega, onde sinaliza que o fato de assegurar a memória de todas as fases do processo, constitui um protocolo legal que possibilita garantir a idoneidade do caminho que a amostra percorreu. E, segundo Smith et al:

A cadeia de custódia contribui para manter e documentar a história cronológica da evidência, para rastrear a posse e o manuseio da amostra a partir do preparo do recipiente coletor, da coleta, do transporte, do recebimento, da análise e do armazenamento. Inclui toda a sequência de posse (SMITH et al, 1990, p. 503).

Já com o olhar arquivístico, Flores (2015), enfatiza que a manutenção da cadeia de custódia deve ser feita através de Ambientes Autênticos, com os Sistemas Informatizados de Gestão Arquivística de Documentos (SIGAD’s), nas fases corrente e intermediária, e com os Repositórios Digitais Confiáveis Arquivísticos (RDC-Arq), na fase permanente.

Figura 2 - Cadeia de Custódia do documento digital

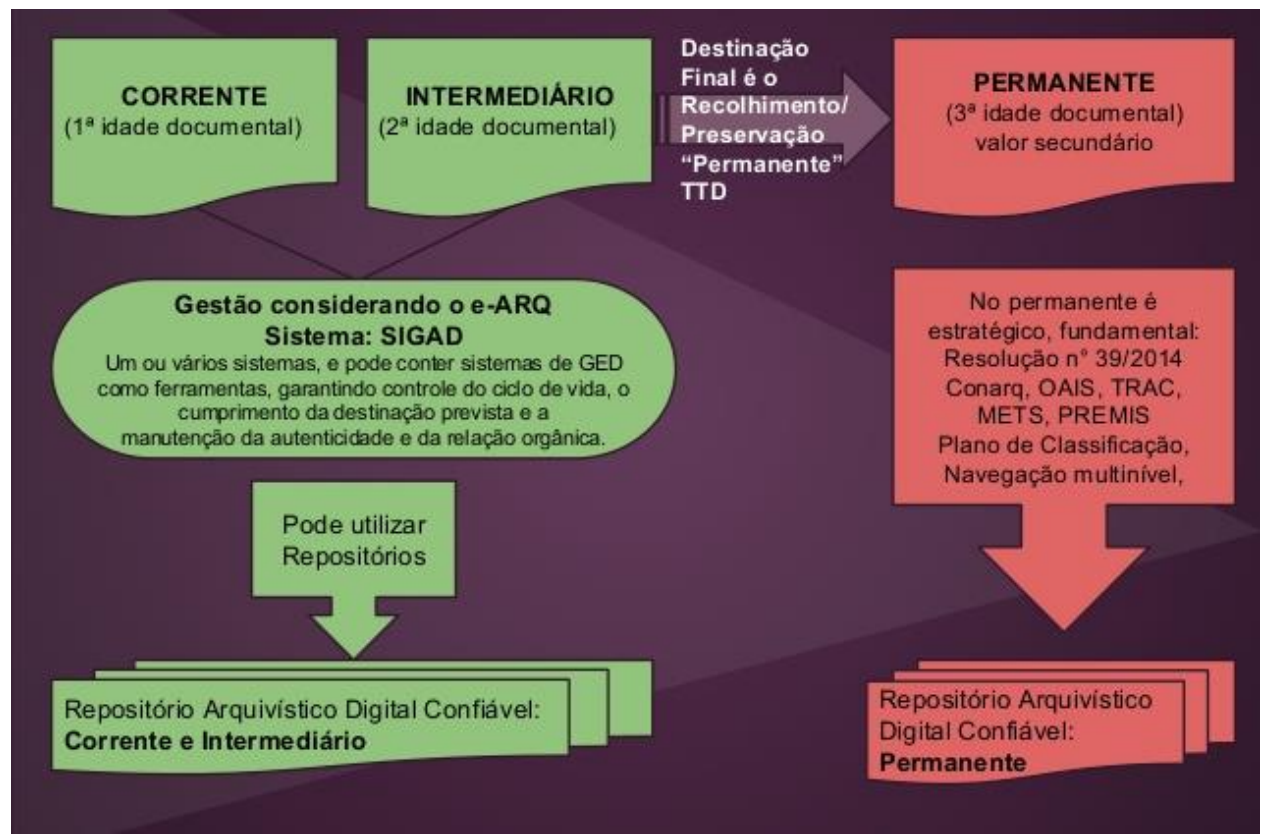

Fonte: Flores (2016). 
$\mathrm{Na}$ figura 2 elaborada por Flores (2016), fica claro que na passagem dos documentos dos sistemas SIGADs para o Repositório Arquivístico Digital Confiável, ocorre uma alteração na cadeia de custódia sem haver interrupção, pois mantém uma linha contínua de custodiadores de documentos arquivísticos (desde o seu produtor, até seu legítimo sucessor) pela qual se assegura que esses documentos são os mesmos desde o início, não sofreram nenhum processo de alteração e, portanto, caracterizados como autênticos.

\section{Modelos de sistemas arquivísticos}

A partir desse arcabouço teórico proporcionado pela fundamentação teórica obtida, apresenta-se os modelos de sistemas, que integrados, serão capazes de realizar o ciclo de vida dos documentos digitais, mantendo sua cadeia de custódia e assim garantindo a preservação dos mesmos.

\section{O sistema informatizado de gestão arquivística de documentos - sigad}

Para construir os fundamentos teóricos e o entendimento do conceito e utilização do Sistema Informatizado de Gestão Arquivística de Documentos (SIGAD), foi estudado o Modelo de Requisitos para Sistemas Informatizados de Gestão Arquivística de Documentos: e-Arq Brasil, e as Orientações para contratação de SIGAD, elaborada pela Câmara Técnica de Documentos Eletrônicos (CTDE).

O e-Arq Brasil define um SIGAD como o sistema que controla o ciclo de vida dos documentos arquivísticos, e orienta que a implementação dele pode ser realizada por um único software ou pela integração de diversos softwares.

Um SIGAD ${ }^{1}$ tem como foco o controle completo do ciclo de vida do documento, desde a captura (independentemente do sistema ou ferramenta que o produziu) até a destinação final, seguindo os procedimentos da gestão arquivística de documentos.

${ }^{1}$ BRASIL. Conselho Nacional de Arquivos. Câmara Técnica de Documentos Eletrônicos. e-ARQ Brasil: Modelo de Requisitos para Sistemas Informatizados de Gestão Arquivística de Documentos. Versão 1.1. Rio de Janeiro: Arquivo Nacional, 2011. 136 p.; 29,7 cm. Versão adotada pelo Conselho Nacional de Arquivos em dezembro de 2009. 
O Modelo de Requisitos para Sistemas Informatizados de Gestão Arquivística de Documentos: e-Arq Brasil, (2011, p. 11-12) definem os requisitos arquivísticos que caracterizam um SIGAD:

a) Captura, armazenamento, indexação e recuperação de todos os tipos de documentos arquivísticos;

b) Captura, armazenamento, indexação e recuperação de todos os componentes digitais do documento arquivístico como uma unidade complexa;

c) Gestão dos documentos a partir do plano de classificação para manter a relação orgânica entre os documentos;

d) Implementação de metadados associados aos documentos para descrever os contextos desses mesmos documentos (jurídico-administrativo, de proveniência, de procedimentos, documental e tecnológico);

e) Integração entre documentos digitais e convencionais;

f) Foco na manutenção da autenticidade dos documentos;

g) Avaliação e seleção dos documentos para recolhimento e preservação daqueles considerados de valor permanente;

h) Aplicação de tabela de temporalidade e destinação de documentos;

i) Transferência e recolhimento dos documentos por meio de uma função de exportação;

j) Gestão de preservação dos documentos.

O SIGAD possibilitará que os documentos permaneçam autênticos e acessíveis para sua guarda nas fases corrente e intermediária, porém, segundo a Orientação Técnica $\mathrm{n}^{\circ} 1$ de (2011, p. 2) da CTDE "um SIGAD não compreende as funcionalidades necessárias para a guarda de documentos permanentes, isto é, não tem por objetivo implementar todos os procedimentos de preservação digital necessários aos documentos de guarda permanente".

A partir desse entendimento, fica evidenciado necessidade da utilização de mais um software para a preservação dos Documentos Digitais. Sendo assim, será apresentado a seguir o referencial teórico que permitirá o entendimento e dará subsídios para a escolha do sistema mais adequado a ser implementado pelo Instituto. 


\section{Repositório digital confiável - rdc-arq}

Para dar início a apresentação da fundamentação teórica do que tange o Repositório Digital Confiável, é preciso esclarecer a diferença entre a gestão documental realizada pelo SIGAD, e o gerenciamento de documentos feito pelo RDC-Arq. O SIGAD faz a gestão arquivística dos documentos, e o RDC-Arq gerencia aspectos como o armazenamento seguro e a aplicação sistemática de estratégias de preservação.

Segundo a Resolução $n^{\circ}$ 43/2015 do CONARQ, a preservação dos documentos arquivísticos digitais, nas idades corrente, intermediária e permanente, deve estar associada a um Repositório Digital Confiável. Esse Repositório deve gerenciar os documentos e metadados de acordo com as práticas e normas da Arquivologia, relacionadas à gestão documental, descrição arquivística multinível e preservação, além de resguardar as características do documento arquivístico, em especial a autenticidade e a relação orgânica entre os documentos.

Partindo para analisar os aspectos necessários que caracterizam um RDC-Arq, foi estudado o relatório "Trusted Digital Repositories: attributes and responsibilities" (RLG/OCLC, 2002, p.13), onde aponta que os repositórios digitais confiáveis devem:

a) Aceitar, em nome de seus depositantes, a responsabilidade pela manutenção dos materiais digitais;

b) Dispor de uma estrutura organizacional que apoie não somente a viabilidade de longo prazo dos próprios repositórios, mas também dos materiais digitais sob sua responsabilidade;

c) Demonstrar sustentabilidade econômica e transparência administrativa;

d) Projetar seus sistemas de acordo com convenções e padrões comumente aceitos, no sentido de assegurar, de forma contínua, a gestão, o acesso e a segurança dos materiais depositados;

e) Estabelecer metodologias para avaliação dos sistemas que considerem as expectativas de confiabilidade esperadas pela comunidade;

f) Considerar, para desempenhar suas responsabilidades de longo prazo, os depositários e os usuários de forma aberta e explícita;

g) Dispor de políticas, práticas e desempenho que possam ser auditáveis e mensuráveis; 
h) Observar os seguintes fatores relativos às responsabilidades organizacionais e de curadoria dos repositórios: escopo dos materiais depositados, gerenciamento do ciclo de vida e preservação, atuação junto a uma ampla gama de parceiros, questões legais relacionadas com a propriedade dos materiais armazenados e implicações financeiras.

Para garantir a presunção de autenticidade e manter preservada a Cadeia de Custódia dos Documentos, o RDC-Arq recolhe os documentos do SIGAD, após findar a fase de Gestão de Documentos. Também é possível recolher para o RDC-Arq, documentos digitalizados, vídeo de monitoramento institucional, e-mails, fotografias, websites/portais.

Para Arrellano (2012, p. 12) um aspecto que caracteriza o Repositório Digital é “o uso de padrões abertos para garantir que o conteúdo estará acessível e que ele poderá ser pesquisado e recuperado para seu uso a longo prazo".

Segundo o CONARQ (2014, p. 9), um Repositório Arquivístico Digital Confiável (RDC-Arq) "é um repositório digital que é capaz de manter autênticos os materiais digitais, de preservá-los e prover acesso a eles pelo tempo necessário”.

Pensando em um Repositório para atender a demanda do IF Baiano, é possível caracterizá-lo como um Repositório Institucional, pois ele abrigará todo os acervos, independentemente de sua temática, em apenas um Repositório Digital Confiável. Para Lynch (apud Café et al, 2003, p. 5), o Repositório Institucional é "um conjunto de serviços que uma universidade oferece aos membros da sua comunidade, para a gestão e disseminação de materiais digitais, criados pela instituição e pelos seus membros".

\section{Metodologia da pesquisa}

O critério metodológico adotado para essa proposta iniciou-se com uma pesquisa exploratória, que nos possibilitou fornecer um norte teórico ao trabalho e dar início ao levantamento bibliográfico, estudo das leis, decretos e portarias relativos à Gestão de Arquivos e Protocolos, a análise da situação atual da Preservação dos Documentos no Instituto, através da aplicação de questionário estruturado de avaliação, encaminhado via email Institucional.

Para Gil (2008, p. 26), a pesquisa tem um caráter pragmático, é um "processo formal e sistemático de desenvolvimento do método científico. O objetivo fundamental da 
pesquisa é descobrir respostas para problemas mediante ao emprego de procedimentos científicos".

Visando responder à questão investigativa neste trabalho, optou-se por realizar uma pesquisa que tivesse o cunho qualitativo e também o quantitativo, para que fosse possível analisar diversos aspectos desse estudo. Segundo Minayo (2013), o método qualitativo:

Caracteriza-se pela empiria e pela sistematização progressiva de conhecimento até a compreensão da lógica interna do grupo ou do processo em estudo. Por isso, é também utilizado para a elaboração de novas hipóteses, construção de indicadores qualitativos, variáveis e tipologias (MINAYO, 2013, p. 57).

Trata-se de uma pesquisa qualitativa e também quantitativa, fundamentada no pensamento de autores como Laville e Dionne (1999), que descrevem esse cenário dizendo que, quando a pesquisa é centrada em um problema específico, provoca o pesquisador a escolher a abordagem mais adequada. Para se chegar à compreensão desejada, pode-se escolher a abordagem quantitativa, qualitativa ou a mistura de ambas. O ideal é que a opção escolhida abarque o objeto da pesquisa e que consiga extrair as melhores informações dos aspectos a serem estudados em torno do problema. Os autores afirmam que o conjunto de dados quantitativos e qualitativos se completam, visto que a realidade demonstrada interage de maneira dinâmica. Seguindo esse entendimento, Flick (2009, p. 43) diz que, "métodos qualitativos e quantitativos devem ser vistos como campos complementares, e não rivais".

O delineamento da metodologia caminhará para um estudo de caso, envolvendo um estudo aprofundado de qual modelo de Sistema e Programa de Gestão Documental deverá ser proposto para o IF Baiano. Gil (2010, p. 37) afirma que o estudo de caso "consiste no estudo profundo e exaustivo de um ou mais objetos, de maneira que permita seu amplo e detalhado conhecimento".

Segundo Stake (1994), é cabível o estudo de caso em pesquisas em que o objeto de estudo é uma pessoa, um programa, uma instituição, uma empresa ou um determinado grupo de pessoas.

O estudo de caso foi escolhido visando realizar uma investigação que permitisse conhecer as características reais, peculiares e os significados da situação estudada, o que pode contemplar o contexto, de acordo com o proposto por Yin (2001).

No desenvolvimento desse projeto de intervenção, a intenção é de ir além da descrição do objeto de estudo. Yin (2005, p. 33) afirma que "o estudo de caso é uma 
estratégia de pesquisa abrangente", além de ser "uma investigação empírica que investiga um fenômeno contemporâneo dentro do seu contexto na vida real" (YIN, 2005; p. 32).

Esta pesquisa teve como campo empírico o Instituto Federal de Educação, Ciência e Tecnologia Baiano (IF Baiano), e como sujeitos da pesquisa os servidores que trabalham diretamente com setores de atividades de Protocolo, Arquivos Administrativos e Arquivos Acadêmicos nos 10 Campi que estão em pleno funcionamento e também na Reitoria.

Iniciou-se a coleta de dados da pesquisa utilizando os elementos extraídos da pesquisa realizada no Plano de Desenvolvimento Institucional (PDI) 2015-2019 do IF Baiano, seguindo a concepção de que a pesquisa documental utiliza-se de elementos diferenciados da pesquisa bibliográfica, pois são baseados na autenticidade de documentos geralmente oriundos de fontes primárias ou secundárias, como pode ser percebido em Pádua:

É aquela realizada a partir de documentos, contemporâneos ou retrospectivos, considerados cientificamente autênticos (não-fraudados); tem sido largamente utilizada nas ciências sociais, na investigação histórica, a fim de descrever/comparar fatos sociais, estabelecendo suas características ou tendências; além das fontes primárias, os documentos propriamente ditos, utilizam-se as fontes chamadas secundárias, como dados estatísticos, elaborados por institutos especializados e considerados confiáveis para a realização da pesquisa (PÁDUA, 2004, p. 68).

Em seguida utilizou-se o relatório de produção de documentos extraído do sistema SIGA, usado atualmente pelo Instituto, do período compreendido entre 2013 a 2015, para analisar de forma quantitativa o volume documental produzido pela Instituição nesse período, com o objetivo de servir como base para elaboração do planejamento da estrutura, das tecnologias e do quantitativo de pessoal necessário para realização dessas atividades.

Para obter informações dos servidores que realizam atividades de protocolo e arquivo no Instituto, foi elaborado como instrumento de pesquisa três questionários. Segundo Oliveira (2008), o questionário é uma técnica utilizada para obtenção de informações, crenças, sentimentos, expectativas e sobre todo e qualquer dado que o pesquisador deseja registrar para atender aos objetivos de seu estudo.

Por entender que é preciso ter aspectos éticos na pesquisa, não houve malefícios aos envolvidos, pois foi garantido total sigilo de suas identidades e das informações prestadas, bem como foi dado a cada um deles, individualmente, a opção de desistir da participação em qualquer momento da coleta de dados, dando-lhes a liberdade de escolha em qualquer momento do processo. 
Análise dos dados extraídos do relatório de criação de processos administrativos do sistema integrado de gestão acadêmica - siga do IF baiano

Extraiu-se do Sistema SIGA, com o apoio da Diretoria de Tecnologia da Informação do IF Baiano, um relatório de produção dos documentos do período compreendido entre 2013 a 2015, para que se possa analisar esse volume de produção.

Em seguida, será apresentada a tabela de criação de processos no Instituto, a partir dessa tabela será possível realizar o planejamento do espaço físico para sua guarda. $\mathrm{Na}$ perspectiva de criação desses documentos em formato digital, seria possível mensurar a média de espaço digital necessário no servidor, além de analisar a viabilidade de centralização da abertura desses processos por setores de protocolos e unidades protocolizadoras, tendo em vista que, atualmente, os processos do IF Baiano são criados por qualquer servidor, sem seguir os padrões arquivísticos.

Tabela 1 - Criação de Processos

\begin{tabular}{|l|r|r|r|r|}
\hline Campus & $\mathbf{2 0 1 3}$ & $\mathbf{2 0 1 4}$ & $\mathbf{2 0 1 5}$ \\
\hline Reitoria & 2.401 & 1.865 & 1.961 \\
\hline Bom Jesus Da Lapa & 182 & 168 & 218 \\
\hline Catu & 765 & 660 & 816 \\
\hline Governador Mangabeira & 206 & 422 & 388 \\
\hline Guanambi & 545 & 666 & 560 \\
\hline Itapetinga & 391 & 309 & 443 \\
\hline Santa Inês & 721 & 552 & 563 \\
\hline Senhor Do Bonfim & 466 & 552 & 848 \\
\hline Teixeira De Freitas & 335 & 624 & 729 \\
\hline Uruçuca & 573 & 754 & 1.046 \\
\hline Valença & 264 & 613 & 640 \\
\hline
\end{tabular}

Fonte: Relatório extraído do Sistema SIGA.

A tabela de criação de processo nos permite perceber como é grande o desafio de elaborar uma gestão capaz de criar, controlar e preservar esses documentos, devido ao volume, a falta de profissionais especialistas para todos os Campi, e por ser um Instituto Multicampi. É possível identificar também que é extremamente necessário que a 
Instituição adote a cultura de criação do documento já em formato digital, pois com o nível de produção atual de documentos no formato de papel, é extremamente complicado realizar a gestão, preservação e dar acesso ao usuário.

Para fortalecer o entendimento da situação atual do Instituto, analisar-se-á os resultados da aplicação do questionário aos três grupos (aos servidores que desempenham atividade de protocolo, arquivo administrativo e arquivo acadêmico) que foi definido na metodologia dessa pesquisa, apresentada no capítulo anterior.

\section{Análise dos dados dos questionários aplicados}

A aplicação dos questionários foi dividida nos três grupos, e para cada grupo foi elaborado um questionário específico. O primeiro grupo a ser analisado será o de servidores que desempenham atividades de protocolo.

Para analisar os dados do questionário, serão apresentados alguns gráficos para ilustrar a pesquisa:

Gráfico 1 - Pergunta ${ }^{\circ} 1$ do questionário de atividades de protocolo

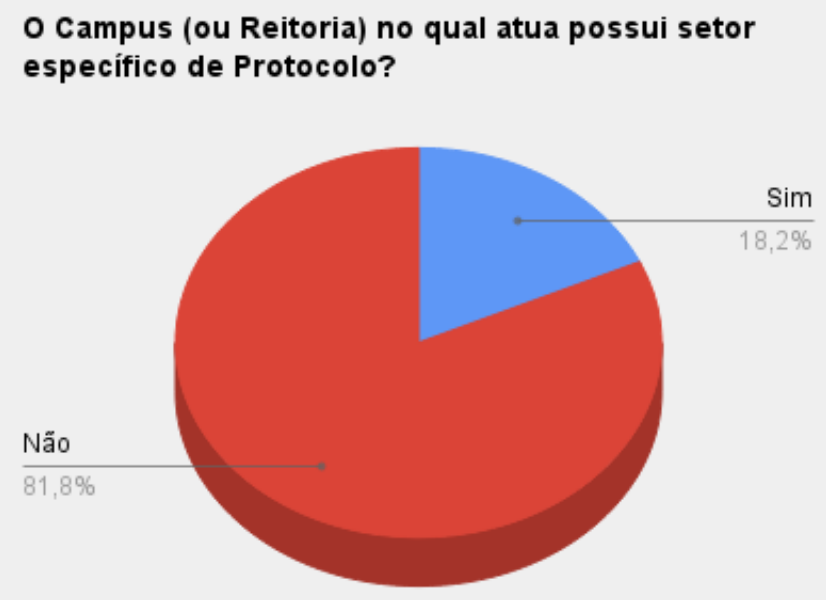

Fonte: Elaborado a partir dos dados do questionário de atividades de protocolo.

Com a aplicação do questionário, pôde-se confirmar a informação contida no PDI do Instituto, onde retrata que só existem dois setores de protocolo na Instituição, que estão 
localizados na Reitoria e no Campus Bom Jesus da Lapa, caracterizando apenas 18,2\% do IF Baiano contemplado por esses setores.

Um dado bastante preocupante, pois segundo o Conselho Nacional de Arquivos, o Protocolo é:

Denominação geralmente atribuída a setores encarregados do recebimento, registro, distribuição e movimentação de documentos em curso, denominação atribuída ao próprio número de registro dado ao documento, e livro de registro de documentos recebidos e/ou expedidos. (CONARQ apud PAES, 2005, p. 27)

Em vista disso, como se pode pensar em um Campus sem setor de protocolo? Como os documentos serão produzidos, recebidos e distribuídos? Como será feita a gestão dos documentos se não existem setores e nem profissionais da área arquivista para isso? É necessário que haja mudanças nesse modelo de gestão, pois essa situação compromete todo o ciclo de vida dos documentos.

Pode-se identificar que em quase todos os Campi, por não existir setor de protocolo, algumas das tarefas básicas atribuídas a esse tipo de setor são realizadas pelos chefes de gabinetes de cada Campus. Segundo a pesquisa, 36,4\% desses profissionais executam essas atividades a apenas um ano, e 45,5\% desses já possuem até 3 anos, realizando rotinas que deveriam ser de setores de protocolo.

O segundo grupo que participou da pesquisa foram os servidores que atuam com arquivos administrativos, escolheu-se o arquivo de Recursos Humanos de cada Campus e também da Reitoria para a aplicação dos questionários, tendo em vista o volume de documentos produzidos e arquivados pelo RH.

Iniciou-se o questionário para esse grupo com a seguinte pergunta:

Gráfico 2 - Pergunta $n^{\circ} 1$ do questionário de arquivos administrativos

o campus (ou Reitoria) no qual atua possui setor especifico de Arquivo?

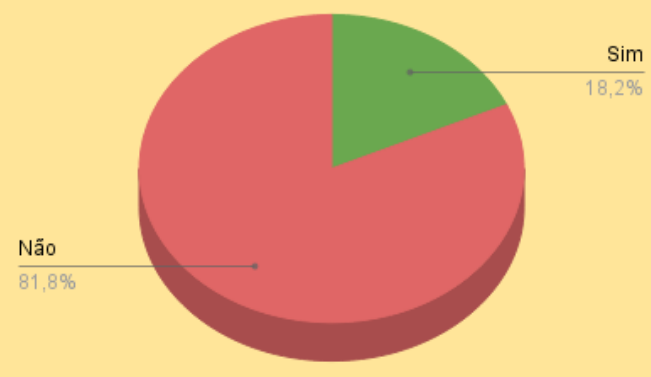


Fonte: Elaborado a partir dos dados do questionário de arquivos administrativos.

Analisando o gráfico anterior, percebe-se o nível de gestão que está sendo realizada para os documentos do Instituto. Uma Instituição de Ensino não deve atuar arquivando seus documentos apenas nos armários próximos a quem os produziu ou recebeu, pois os documentos, após cumprir sua fase corrente, não devem mais ficar ocupando as salas de trabalho ou atendimento. Cada Campus precisa ter seu setor de arquivo, mas a pesquisa mostra que apenas $18,2 \%$ dos setores de arquivos administrativo de $\mathrm{RH}$ possuem um arquivo propriamente dito.

Dando continuidade às perguntas, pode-se perceber na questão $n^{\circ} 3$ do questionário a diversidade de profissionais exercendo atividades de arquivo administrativo:

Gráfico 3 - Pergunta $n^{\circ} 3$ do questionário de arquivos administrativos

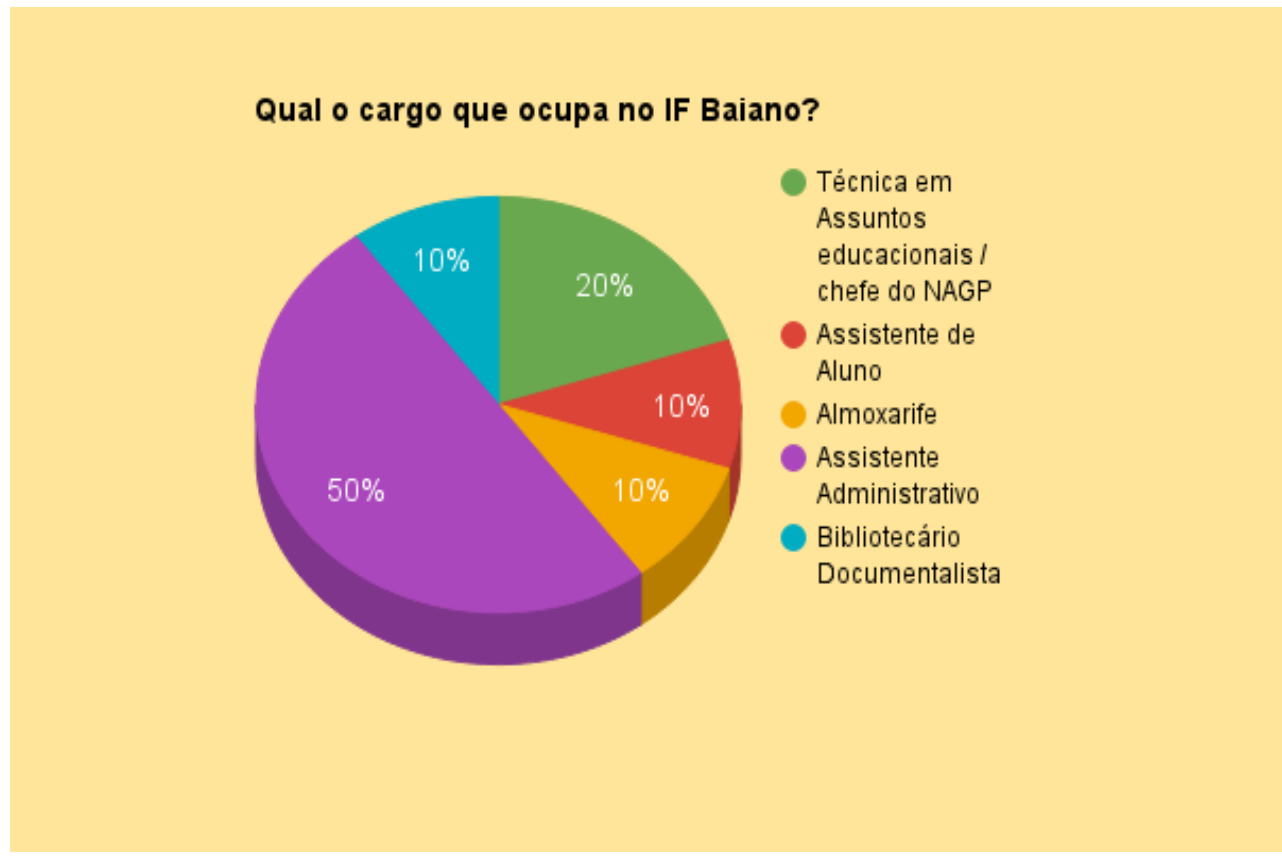

Fonte: Elaborado a partir dos dados do questionário de arquivos administrativos.

O cargo de Assistente Administrativo possui 50\% dessa ocupação e o restante são ocupados por cargos diversos. A pesquisa mostra que não existe profissionais com formação arquivística atuando nos arquivos dos Campis. Só existe um Arquivista na Instituição e esse está lotado na Reitoria, ele não participou dessa pesquisa por ser o idealizador da mesma. Na perspectiva de melhoria dessa realidade, foram nomeados no 
segundo semestre de 2016, nove Técnicos em Arquivo para o Instituto, mas que ainda não estão atuando diretamente com esses setores.

Baseado no questionário aplicado, a questão $n^{\circ} 4$, perguntou-se se o servidor já realizou algum curso relacionado a área de Arquivo, e 81,8\% dos profissionais que estão atuando nesses setores responderam que nunca fizeram um curso relacionado a área de arquivo. Dado que deve ser cuidadosamente observado pelo IF Baiano.

Quando perguntou-se aos servidores na questão $\mathrm{n}^{\circ} 5$ se eles possuem espaço físico e equipamentos adequados para desenvolver essas atividades, 54,5\% disseram que não possuem e $45,5 \%$ disseram que a estrutura atende as necessidades.

Seguindo a análise dos dados coletados, serão apresentados agora os resultados da aplicação do questionário ao grupo de servidores que desempenham atividades de arquivo nas secretarias acadêmicas dos Campi. Escolheu-se esse grupo como referência para avaliar a gestão dos documentos acadêmicos, em virtude do volume de produção e recebimento de documentos, pois concentra nesse ambiente a informação registrada dos alunos de nível médio/técnico, da graduação e da pós-graduação.

Primeiramente, buscou-se entender se existe um setor específico para o tratamento e arquivamento desses documentos, ou se eles são guardados no mesmo ambiente da secretaria. Pensando assim, elaborou-se a questão a seguir que será apresentada através de gráfico para ilustrar melhor esses dados:

Gráfico $4-$ Pergunta $\mathrm{n}^{\circ} 1$ do questionário de arquivos acadêmicos

O Campus no qual atua possui setor específico de Arquivo Acadêmico?

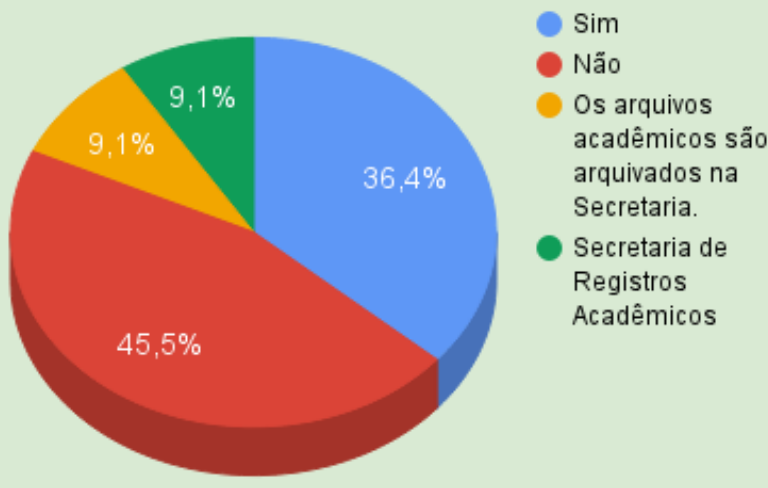

Fonte: Elaborado a partir dos dados do questionário de arquivos acadêmicos. 
A partir da análise do gráfico da questão, pode-se concluir que apenas 36,4\% dos Campi possuem um setor de arquivo acadêmico, pois tanto os $45,5 \%$ que responderam que não e os $18,2 \%$ que responderam que são preservados dentro da própria secretaria acadêmica, na prática, arquivam os documentos no mesmo a local que realizam outras atividades do dia-a-dia. A falta de um espaço adequado para o tratamento e arquivamento dos documentos acadêmicos, pode dificultar a organização e comprometer a preservação, além de criar barreiras para o atendimento rápido e eficiente às solicitações dos usuários.

Com o entendimento da estrutura atual dos Campi, no que diz respeito ao espaço para execução das atividades de arquivo acadêmico, parte-se agora para compreender através da segunda questão quanto tempo esses servidores atuam na execução dessas atividades. Foi possível identificar a partir das respostas que 45,5\% dos participantes já estão de 1 a 3 anos desenvolvendo esse trabalho, e 27,3\% possuem de 3 a 5 anos, e uma parcela também com 27,3\% já atuam a mais de 5 anos. Interpretando esse cenário, identificou-se que o problema de falta de espaço adequado e a não implementação de técnicas adequadas para a gestão desses documentos é uma questão que permeia há anos na Instituição. Isso ficou evidente quando realizou-se a seguinte pergunta:

Gráfico 5 - Pergunta ${ }^{\circ} 3$ do questionário de arquivos acadêmicos

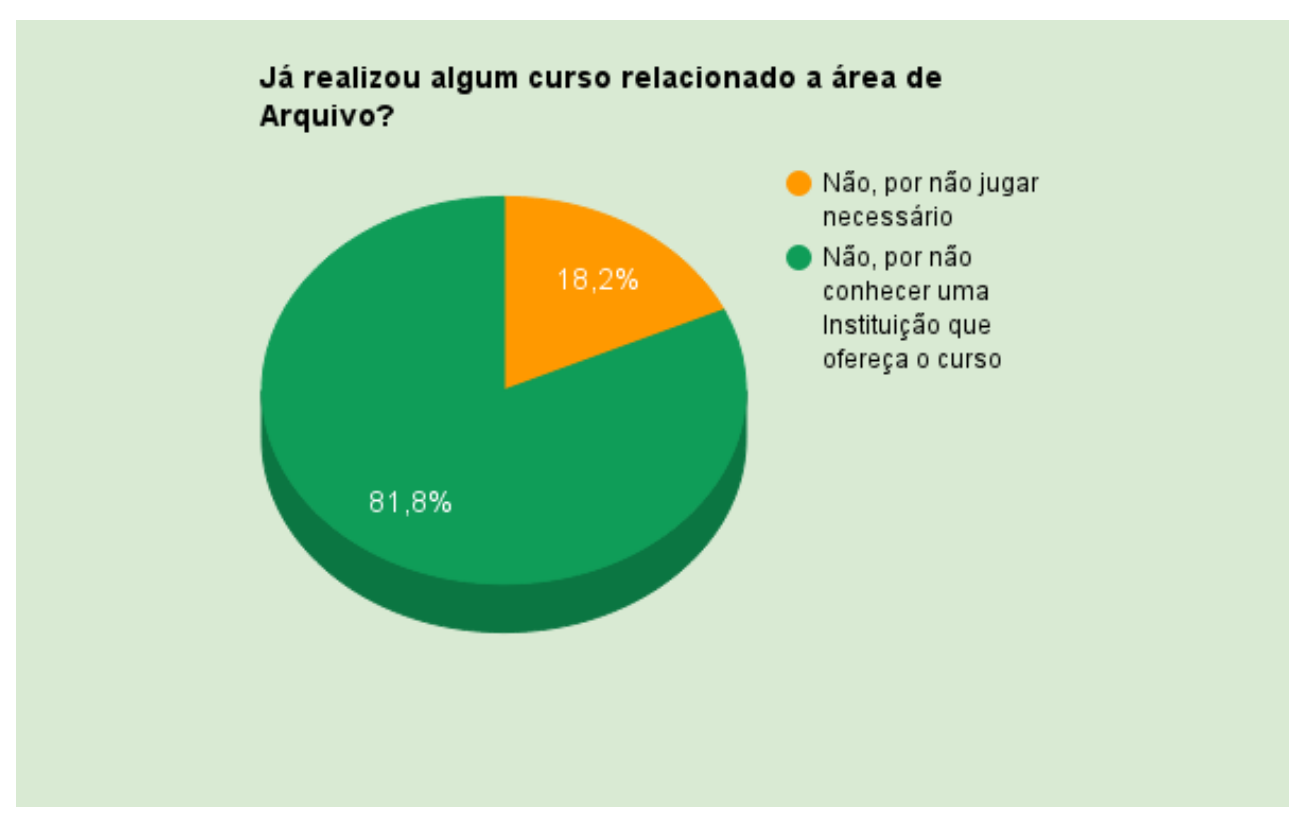

Fonte: Elaborado a partir dos dados do questionário de arquivos acadêmicos. 
O gráfico anterior é o retrato da falta de formação básica da área arquivística e da visão simplista que alguns profissionais possuem sobre essas atividades, por desconhecerem as técnicas que deveriam ser aplicadas aos documentos e por não estarem familiarizados com as leis e normas que regem a arquivologia. A Universidade Federal da Bahia - UFBA, criou a Graduação em Arquivologia em 1997, no Instituto de Ciência da Informação, mas ainda hoje, muitas pessoas desconhecem a importância desse profissional no próprio Estado onde existe o curso. E quem paga essa conta é o Instituto, por correr o risco de ver sua história se perder, e o usuário por não ter a segurança de que vai conseguir obter as informações necessárias que estão contidas nesses documentos quando ele precisar.

Quando foi perguntado se o servidor possui espaço físico e equipamentos adequados para desenvolver as atividades de arquivo, 54,5\% dos participantes responderam que possuem e 45,5\% disseram que não. O gráfico a seguir ilustra bem essa situação:

Gráfico 6 - Pergunta ${ }^{\circ} 4$ do questionário de arquivos acadêmicos

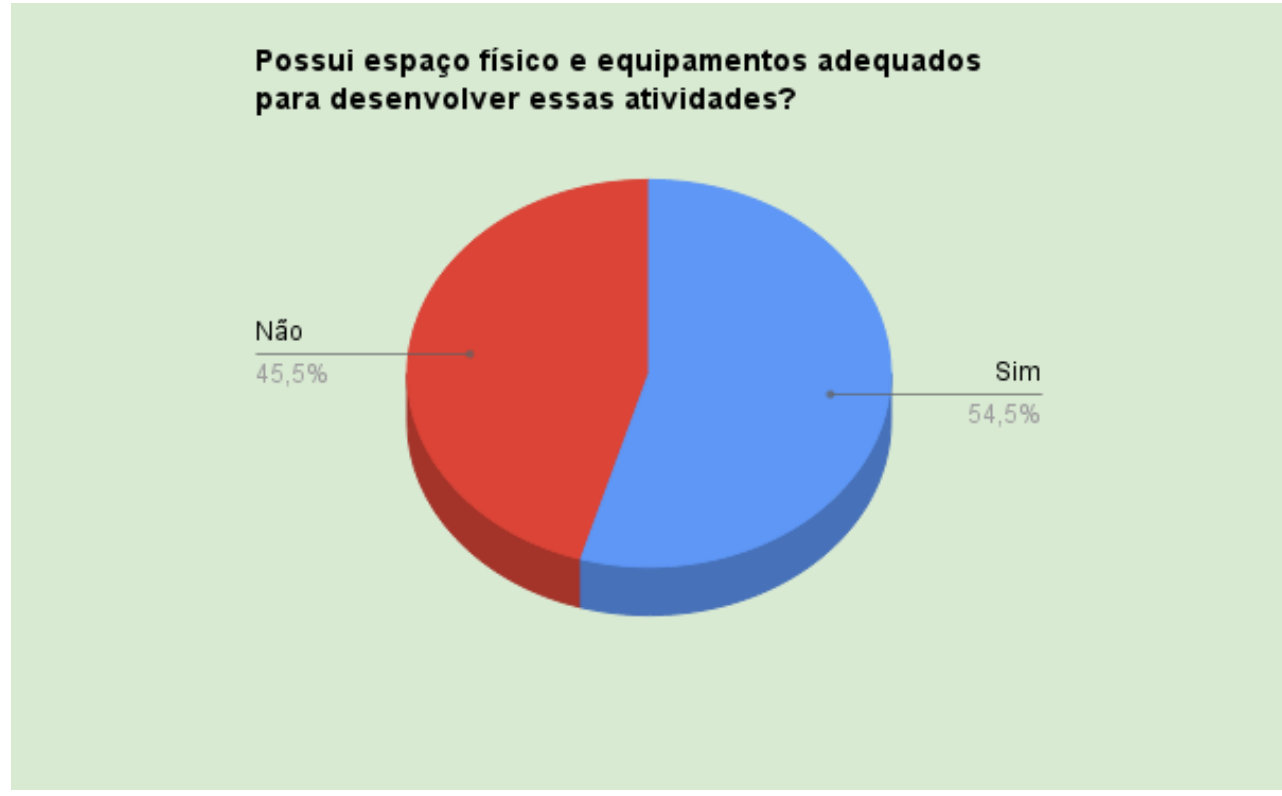

Fonte: Elaborado a partir dos dados do questionário de arquivos acadêmicos.

É possível compreender que as respostas caracterizam que a maioria dos servidores que desempenham as atividades de arquivo, acreditam que é possível realizar essas atividades de maneira simples e da forma que historicamente vinha sendo feita, sem necessitar de um ambiente adequado e de equipamentos específicos da área. Esse 
pensamento é passível de entendimento, pois muitos dos participantes tem essa concepção devido à falta de informação, tendo em vista que foi em virtude da rotina de trabalho que eles passaram a realizar essas atividades sem o preparado adequado.

Pensando em compreender o pensamento dos entrevistados com relação aos documentos em formato digital, fez-se a seguinte pergunta: A criação, tramitação, uso e arquivamento dos dossiês de alunos em meio digital, através de um sistema, sem usar papel, iria facilitar a rotina de trabalho e otimizar tempo no acesso as informações? E $81,8 \%$ dos servidores concordaram completamente com a questão, 9,1\% concordaram parcialmente e também $9,1 \%$ discordaram parcialmente. A partir da análise desses dados coletados, é possível constatar que a maioria dos participantes enxergam que o uso dos documentos em formato digital iria otimizar as rotinas de trabalho e facilitar o acesso à informação contida nos documentos.

\section{Produtos da pesquisa}

Após o estudo da bibliografia especializada, da análise da produção dos documentos, da análise das tecnologias de informação e comunicação que estão sendo utilizadas em outras instituições para a gestão, preservação dos documentos, e da situação atual do IF Baiano no que se refere à preservação dos seus documentos a longo prazo, percebeu-se a necessidade de elaborar dois produtos da pesquisa. Até chegar à definição desses dois produtos, foi essencial a realização de um estudo interdisciplinar, para entender um pouco mais do Direito, da Administração, da Análise de Sistema, e aprofundamento da Arquivologia na Era Digital.

Após o estudo, foi definido como o primeiro produto uma "Proposta de Criação do Sistema de Arquivos para o IF Baiano". Para fundamentar essa proposta, apresenta-se o conceito extraído do Dicionário de Terminologia Arquivística, publicado pela Associação dos Arquivistas Brasileiros, que define Sistema de Arquivos como:

Conjunto de arquivos de uma mesma esfera governamental ou de uma mesma entidade, pública ou privada, que independentemente da posição que ocupam nas respectivas estruturas administrativas, funcionam de modo integrado e articulado na consecução de objetivos técnicos comuns. (DICIONÁRIO DE TERMINOLOGIA ARQUIVÍSTICA, 1996, p. 7).

Nesse sentido, entende-se que para o desenvolvimento de uma Gestão dos Documentos eficiente, é de fundamental importância a criação, implantação e operacionalização de um Sistema de Arquivos, através da aprovação de resolução aprovada 
pelo órgão máximo deliberativo do IF Baiano, para garantir e agilizar o acesso aos documentos produzidos e recebidos em cumprimento às atribuições do Instituto e para garantir eficiência e eficácia às atividades administrativas e acadêmicas. A resolução constituirá a base jurídica, no âmbito institucional, para sustentar a gestão documental na Instituição. A implantação de um Sistema que integre a Reitoria aos Campi é o elemento essencial para oportunizar a informação útil e exata aos processos de tomada de decisão, bem como para garantir a preservação da memória institucional que servirá de referência, informação, prova ou fonte de pesquisa.

Porém, algumas dificuldades podem ser encontradas para a implementação desse sistema, Di Mambro (2014, p. 128) ressalta bem essa questão “O primeiro desafio a se enfrentar na criação e implantação de um sistema de arquivos está representado pela própria instituição, com a sua cultura organizacional e política interna".

Nesse sentido, é preciso que sejam realizadas ações de comunicação, de forma institucionalizada, com o objetivo de mostrar a importância dos arquivos para a administração, setores acadêmicos e para a preservação da memória da Instituição, pois a gestão documental é uma exigência da Lei 8.159/91 para os órgãos públicos. É necessário que o Sistema possua uma estrutura bem definida e organizada, para que não ocorra dificuldade na implementação e na gestão do sistema, transferindo os mesmos problemas de gestão documental do suporte convencional para o meio eletrônico.

A estruturação desse Sistema é extremamente necessária, pois com a sanção da Lei $\mathrm{n}^{\circ}$ 12.527/2011 - Lei de Acesso à Informação, ficou estabelecido que é direito de qualquer pessoa solicitar informações produzidas ou guardadas por órgãos e entidades públicas; e que o acesso às informações públicas é fundamental para consolidação da democracia, pois possibilita aos cidadãos participarem efetivamente das decisões que os afetam. Logo, o Instituto não conseguirá atender as demandas geradas a partir da Lei sem ter uma gestão eficiente de seus arquivos e protocolos.

O Sistema proposto tem o caráter inovador, pois foge dos modelos já existentes em outras instituições, ele está estruturado de forma que seu principal pilar não é a construção de espaços para abrigar a massa documental da Instituição e, sim, a utilização das Tecnologias de Informação e Comunicação - TICs, como ferramentas necessárias para modernizar e otimizar a gestão e preservação dos documentos da Instituição.

Para a aplicação das TICs, devem ser levadas em consideração as resoluções e orientações emanadas do CONARQ, referentes a documentos arquivísticos digitais, a fim 
de otimizar o controle e definir a segurança, o custo, a produção, manutenção e preservação dessa informação ao longo do ciclo de vida dos documentos, incluindo-se a produção de documentos oficiais em meio digital, sua tramitação e sua preservação.

A intenção dessa proposta é estruturar o Sistema de forma que a implantação dos softwares necessários para o desenvolvimento das atividades de gestão, preservação aos documentos digitais e analógicos do Instituto não comprometa a preservação da cadeia de custódia, mesmo com a necessidade de migração desses documentos para outros softwares no futuro.

Um Sistema de Arquivos não consegue desenvolver suas atividades se não tiver um Programa de Gestão de Arquivos e Protocolos bem estruturado e definido. Os Programas estabelecem objetivos gerais e específicos focados em determinado tema, público, conjunto institucional ou área geográfica.

Os Programas de Gestão de Arquivos são de fundamental importância para as Instituições Federais de Ensino, pois além de estabelecerem os objetivos gerais e específicos focados nas ações e atividades de gestão de documentos, facilitam a identificação dos problemas e os respectivos segmentos que devem ser alvo de intervenção, e são instrumentos de organização que articulam as ações para enfrentar os problemas.

Pensando assim, elaborou-se como o segundo produto dessa pesquisa a "Proposta de Programa de Gestão Documental do IF Baiano", programa que irá definir o planejamento das ações, tanto para os documentos produzidos em formatos convencionais como, por exemplo, em papel, quanto para a produção dos documentos em formato digital, além de relacionar os sistemas utilizados atualmente no Instituto, com a nova proposta de gestão dos documentos digitais, e sinalizar as metas iniciais do Programa. Decidiu-se então propor a implantação de um Sistema de Gestão e outro de Preservação, que de forma conjunta e inter-relacionada realizarão os procedimentos necessários para garantir a História e Memória da Instituição.

\section{Considerações finais}

$\mathrm{O}$ artigo que ora encerra-se partiu da necessidade de estruturar no IF Baiano uma política arquivística capaz de atender de forma eficiente e eficaz a legislação federal, as demandas dos órgãos governamentais e as necessidades internas do Instituto no que tange a gestão dos documentos de qualquer natureza ou suporte, inclusive os documentos 
digitais, garantindo a preservação dos documentos a longo prazo, garantido a manutenção da História e Memória da Instituição.

A respeito do que se tinha como problemática da pesquisa percebe-se que, embora haja no setor de arquivo da Reitoria a tentativa de aplicar procedimentos para realizar a gestão dos documentos, ainda é uma tentativa local, que esbarra na falta de estrutura física e formação básica dos servidores que realizam atividades de arquivo e protocolo.

No que tange ao objetivo geral, onde se propõe a criação de uma estrutura capaz de gerenciar, integralizar e definir Políticas Arquivísticas considerando os ditames da Era Digital, para a preservação da Informação a longo prazo, foi possível identificar a necessidade de criação dessa estrutura em virtude das dificuldades encontradas pelos setores.

Identificou-se a necessidade de propor dois produtos como instrumentos imprescindíveis para a realização da gestão e preservação dos documentos do IF Baiano. Entende-se que com a criação e implantação do Sistema de Arquivos e do Programa de Gestão Documental propostos como produtos desse trabalho, o Instituto consiga gerenciar seus documentos de forma sistêmica, otimizando e modernizando seus procedimentos.

Nesse sentido, a criação do Sistema de Arquivos permitirá a estruturação dos setores de Arquivo e Protocolo e a implementação das políticas necessárias para o controle da criação, tramitação, definição dos prazos de guarda e preservação dos documentos, gerando benefícios tanto para setores administrativos quanto para os setores acadêmicos.

A pesquisa mostrou que o Instituto necessita implementar sistemas arquivísticos que possibilite a criação e uso de Documentos Digitais, que irão otimizar o desenvolvimento das atividades e proporcionar, assim, maior eficiência e eficácia na Administração Pública.

Com a pesquisa, percebe-se uma grande mudança na compreensão do ciclo de vida dos documentos, pois dentro da abordagem tradicional, esse ciclo era definido muito mais pela disposição física dentro da Instituição. Mas no meio digital são os metadados que vão fazer esse trabalho. Logo se conclui que os princípios arquivísticos continuam válidos, mudando apenas a maneira de aplicação, pois mudam-se os suportes, mas continuam-se com os mesmos princípios.

Foi identificado também que com o advento do suporte digital, o foco não é mais o objeto, mas a garantia de preservação e acesso aos documentos dentro de um universo complexo de objetos binários distintos. 
Ficou evidente que para gerenciar documentos arquivísticos no meio digital, devese levar em conta um nível organizacional ainda maior, pois as aparentes facilidades geram confusões ainda maiores, pela constante multiplicação dos documentos, falta de barreiras físicas e dos acessos simultâneos.

Conclui-se que o sucesso da implantação dessa proposta oriunda da pesquisa depende do comprometimento de todos os servidores do Instituto e da capacitação desses para a realização das atividades. Só assim será possível avançar na perspectiva da construção de uma Gestão e Preservação dos Documentos que possibilite o uso adequado de Documentos Digitais no Instituto.

Espera-se, assim, que essa pesquisa possa servir de inspiração e de ponto de partida para que outros pesquisadores aprofundem o tema, com o intuito de apresentar novos elementos que possam contribuir para que a Gestão e Preservação dos Documentos em qualquer suporte permeie em todas as instituições com sucesso e eficácia.

\section{Referências}

BRASIL. Conselho Nacional de Arquivos. Recomendações para a produção e o armazenamento de documentos de arquivo. Conselho Nacional de Arquivos. Rio de Janeiro: O Conselho, 2005.

Conselho Nacional de Arquivos. Câmara Técnica de Documentos Eletrônicos. eARQ Brasil: Modelo de Requisitos para Sistemas Informatizados de Gestão Arquivística de Documentos. Versão 1.1. Rio de Janeiro: Arquivo Nacional, 2011. 136 p.; Versão adotada pelo Conselho Nacional de Arquivos em dezembro de 2009.

Conselho Nacional de Arquivos. e-ARQ Brasil. Modelo de Requisitos para Sistemas Informatizados da Gestão Arquivística de Documentos. Câmara Técnica de Documentos Eletrônicos. 1.1 versão. 136 p. Rio de Janeiro: Arquivo Nacional, 2011. Disponível: <http://www.siga.arquivonacional.gov.br/images/publicacoes/e-arq.pdf>. Acesso em: 15 abr. 2017.

Conselho Nacional de Arquivos. Resolução nº 37. 19 de dezembro de 2012. Ministério da Justiça Arquivo Nacional Conselho Nacional de Arquivos. Publicado no Diário Oficial da União, Edição n 245, de 20 de dezembro de 2012 - Seção 1.

Constituição da República Federativa do Brasil: promulgada em 05 de outubro de 1988. Organização do texto: Juarez de Oliveira. 4 ed. São Paulo: Saraiva, 1990.

Decreto-lei $\mathrm{n}^{\circ} 8.159$, de 08 de janeiro de 1991 . Dispõe sobre a política nacional de arquivos públicos e privados e dá outras providências. Diário Oficial da União, Brasília, 09 jan. 1991. 
Decreto-lei $\mathrm{n}^{\circ}$. 12.527, de 18 de novembro de 2011. Regula o acesso a informações previsto no inciso XXXIII do art. 5o, no inciso II do $\S 30$ do art. 37 e no $\S 20$ do art. 216 da Constituição Federal; altera a Lei no 8.112, de 11 de dezembro de 1990; revoga a Lei no 11.111 , de 5 de maio de 2005, e dispositivos da Lei no 8.159 , de 8 de janeiro de 1991; e dá outras providências. Diário Oficial da União, Brasília, 18 nov. 2011.

Decreto-lei $n^{\circ} \cdot 9.605$, de 12 de fevereiro de 1998. Dispõe sobre as sanções penais e administrativas derivadas de condutas e atividades lesivas ao meio ambiente, e dá outras providências. Diário Oficial da União, Brasília, 13 de fev. 1998.

CASTRO, Astréa de Moraes et al. Arquvística arquivologia: arquivística = técnica, arquivologia = ciência. Rio de Janeiro: Ao Livro Técnico, 1988. p. 19-20.

DI MAMBRO, Galba Ribeiro. Universidades \& Arquivos: gestão, ensino e Pesquisa. Organização: Renato Venâncio, Adalson Nascimento. Criação e implantação do sistema de arquivos UFJF, p.117-132. Belo Horizonte: Fino Traço, 2014.

DOURADO, Luiz Fernandes. Políticas e Gestão da Educação Básica no Brasil: Limites e Perspectivas. Revista Educ. Soc., Campinas, v. 28, n. 100 - Especial, p. 921-946, out. 2007. Disponível em: <http://www.cedes.unicamp.br>. Acesso em: 25 mar. 2017.

FERREIRA, Miguel. Introdução à preservação digital: conceitos, estratégias e atuais consensos. Guimarães, Portugal: Escola de Engenharia da Universidade do Minho, 2006.

FLORES, Daniel. Interoperabilidade de documentos arquivísticos: dos sistemas de negócio ao SIGAD e ao RDC-Arq. Palestra. Rio de Janeiro - RJ. 73 slides, color, Padrão Slides Google Drive/Docs 4x3. Material elaborado para a Palestra no Comissão Nacional de Energia Nuclear - CNEN. 13 de maio de 2016. Disponível em: $\langle$ http://www.cnen.gov.br/images/CIN/PDFs/Interoperabilidade de DADs.pdf $\rangle$. Acesso em: 13 de out. 2016.

FONTANA, Fabiana Fagundes et al. Archivematica como ferramenta para acesso e preservação digital à longo prazo. ÁGORA ISSN 0103-3557, Florianópolis, v. 24, n. 48, p. 62-82, mar. 2014. ISSN 0103-3557. Disponível em: <https://agora.emnuvens.com.br/ra/article/view/457>. Acesso em: 22 out. 2016

GATTI, Bernadete Angelina. A construção metodológica da pesquisa em educação: desafios. In: RBPAE - v. 28, n. 1, p. 13-34, jan/abr. 2012. Disponível em: <http://docs11.minhateca.com.br/450782800,BR,0,0,Pesquisa_Bernadette_Gatti.pdf >. Acesso em: 22 out. 2016.

GIL, Antônio Carlos. Métodos e técnicas de pesquisa social. 6. ed. São Paulo: Atlas, 2008.

Como elaborar projetos de pesquisa. 5. ed. São Paulo: Atlas, 2010.

INNARELLI, H. C. Gestão da preservação de documentos arquivísticos digitais: proposta de um modelo conceitual. 2015. 35 p. Tese (Doutorado em Ciência da Informação). Escola de Comunicação e Artes, Universidade de São Paulo, 2015. 
JENKINSON, Hilary. A manual of archive administration: including the problems of war archives and archive making. Oxford: The Clarendon Press, 1922.

LOPES, Luís C. A Nova Arquivística na Modernização Administrativa. Rio de Janeiro: Arquivo Público do RJ, 2000. 236 p.

MINAYO, Maria Cecília de Souza. O desafio do conhecimento: pesquisa qualitativa em saúde. 13. ed., São Paulo: Hucitec, 2013.

MOREIRA, José Vitório Tavares. Gestão da Informação em uma Instituição de Ensino Superior: Acadêmicos em Foco. Revista Gestão e Planejamento Salvador. v. 10, n. 2, p. 248-261, jul./dez. 2009.

NOVO, Hildenise Ferreira. Análise conceitual e cognitiva: Modac - um modelo dinâmico para auxiliar a construção de Sistemas de Organização do Conhecimento (SOC). Salvador, 2014, 177 f. Tese (Doutorado Multi-Institucional e Multidisciplinar em Difusão do Conhecimento). Universidade Federal da Bahia, 2014.

PÁDUA, Elisabete M. M. de. Metodologia da pesquisa: abordagem teórico-prática. 10ed. São Paulo: Papirus, 2004.

RONDINELLI, Rosely Curi. Fidedignidade e autenticidade do documento eletrônico: uma abordagem arquivística. In: INTEGRAR - Congresso Internacional de Arquivos, Bibliotecas, Centros de Documentação e Museus, 19. Textos. São Paulo: Imprensa Oficial, 2002. p. 471-483.

SAYÃO, Luis Fernando. Repositórios Digitais Confiáveis para a Preservação de Periódicos Eletrônicos Científicos. Revista do Instituto de Ciência da Informação da UFBA., Salvador, V. 4, n. 3, p. 68-94, dez. 2010. Disponível em: <https://portalseer.ufba.br/index.php/revistaici/article/view/4709/3565>. Acesso em: 10 out. 2016.

SILVA, Edith Maria. Conservação e Restauração de livros e documentos. Cadernos FUNDAP, São Paulo, ano 4, $\mathrm{n}^{\mathrm{o}}$ 8, p. 49, 55, Abril 1984. Disponível: <http://www.fundap.sp.gov.br/publicacoes/cadernos/cad08/Fundap08/CONSERVACAO\% 20E\%20RESTAURACAO\%20DE\%20LIVROS\%20E\%20DOCUMENTOS.pdf >. Acesso em: 16 abr. 2016.

SMITH, M. L; BRONNER; W. E; SHIMOMURA, E. T. et al. Quality Assurance in Drug Testing Laboratories. Clin Lab Med, [S.1], v. 10, n. 3, p. 503-516, 1990. Disponível em: <http://www.labcorp.com/datasets/labcorp/html/chapter/mono/fo000700.htm>. Acesso em: 13 mar. 2016.

THOMAZ, Katia de Padua. A preservação de Documentos Eletrônicos de Caráter Arquivístico: novos desafios, velhos problemas. 2004. 389 p Tese (Doutorado em Ciência da Informação) - Universidade Federal de Minas Gerais, Escola de Ciência da Informação, MG. 2004. 